\title{
Shear Thinning and Hydrodynamic Friction of Viscosity Modifier- Containing Oils. Part II: Impact of Shear Thinning on Journal Bearing Friction
}

\author{
Nigel Marx ${ }^{1} \cdot$ Luis Fernández $^{2} \cdot$ Francisco Barceló $^{2} \cdot$ Hugh Spikes $^{1}$ (I)
}

Received: 24 February 2018 / Accepted: 11 June 2018 / Published online: 21 June 2018

(c) The Author(s) 2018

\begin{abstract}
In a companion paper, the temporary shear thinning behaviour of a series of viscosity-modifier (VM)-containing blends was studied over a wide shear rate and temperature range [Marx et al. in Tribol Lett, https://doi.org/10.1007/s11249-018-10395]. It was found that for almost all VMs the resulting data could be collapsed on a single viscosity versus reduced strain rate curve using time-temperature superposition. This made it possible to derive a single equation to describe the viscosityshear rate behaviour for each VM blend. In the current paper, these shear thinning equations are used in a Reynolds-based hydrodynamic lubrication model to explore and compare the impact of different VMs on the film thickness and friction of a lubricated, isothermal journal bearing. It is found that VMs reduce friction and especially power loss markedly at high shaft speeds, while still contributing to increased hydrodynamic film thickness at low speeds. The model indicates that VMs can contribute to reducing friction in two separate ways. One is via shear thinning. This occurs especially at high bearing speeds when shear rates are large and can result in a 50\% friction reduction compared to the equivalent isoviscous oil at low temperatures for the blends studied. The second is via their impact on viscosity index, which means that for a set viscosity at high temperature the low-shear-rate (and thus the high shear rate) viscosity of a high-VI oil, and consequently its hydrodynamic friction, will be lower at low temperatures than that of a low-VI oil. The identification and quantification of these two alternative ways to reduce friction should assist in the design of new, fuel-efficient VMs.
\end{abstract}

Keywords Viscosity modifier $\cdot$ Viscosity index improver $\cdot$ Shear thinning $\cdot$ Bearing friction $\cdot$ Film thickness $\cdot$ Engine efficiency

\section{Introduction}

Viscosity modifier additives (VMs) are used to increase the viscosity index of lubricants and are key components of most crankcase engine oils. It is well known that their blends exhibit shear thinning at the high shear rates present in lubricated contacts and that the resulting reduction in viscosity leads to thinner lubricant films and lower hydrodynamic friction than predicted in the absence of shear thinning.

In a companion paper, the temporary shear thinning behaviour of a series of VM-containing blends was investigated, including both simple solutions in base oil and full

\footnotetext{
Hugh Spikes

h.spikes@imperial.ac.uk

Imperail College London, London, UK

2 Repsol Technology Centre, Madrid, Spain
}

engine oil formulations [1]. It was found that, with one exception, time-temperature superposition could be used to derive a single equation to describe the viscosity of the $\mathrm{VM}$ blend at any shear rate and temperature for a given blend. Such an equation in conjunction with a hydrodynamic lubrication model makes it possible to explore the impact of VM additives on film thickness and friction in lubricated machine components.

This paper described the application of a generalised Reynolds equation to model hydrodynamic lubrication behaviour of a steadily loaded, isothermal engine journal bearing incorporating temporary shear thinning of the lubricant. This enables the influence of the VM additive on both hydrodynamic film thickness and hydrodynamic friction to be predicted for the oils studied in [1], and the ways that VMs contribute to friction reduction to be determined. 


\section{Background}

Viscosity index improver polymers or viscosity modifiers (VMs) have been used as engine oil additives since the mid1930s and in recent years their application has extended to gear oils, automatic transmission fluids, greases and some hydraulic fluids [2]. Their primary role is to enhance the lubricant viscosity index of their blends [3-5]. This enables the development of multigrade engine oils that combine a reasonably low viscosity at low engine temperatures with sufficient viscosity at high temperature to produce effective hydrodynamic films in engine components.

Engine oil VMs can exhibit temporary shear thinning at the high shear rates present in engine components, including the ring pack and the journal bearings, and for many years this was considered undesirable since it leads to a reduction in hydrodynamic film thickness [6]. However, it is now recognised that in hydrodynamic lubricated contacts temporary shear thinning of engine oils is beneficial for fuel economy and that this may more than compensate for the negative impact of reduced film thickness [7,8], though the effect of permanent shear thinning must also be considered [9].

In a companion paper, Part I [1], the temporary shear thinning properties of a series of $17 \mathrm{VM}$ blends were studied, all having the same HTHS viscosity of $3.7 \mathrm{cP}\left(\right.$ at $\left.10^{6} \mathrm{~s}^{-1}, 150^{\circ} \mathrm{C}\right)$. These are listed in Table 1 as oils \#1 to \#17. Ten were simple solutions of different commercial VMs in the same Group II base oil, while seven included a DI pack and can thus be considered to be fully formulated $15 \mathrm{~W} / 40$ engine oils. Also studied was an additive-free Group IV base oil, \#18, having the same HTHS as that of the VM blends. Further details of all of these oils are provided in [1].

The dynamic viscosity of all the VM-containing oils was measured over a wide shear rate range up to $10^{7} \mathrm{~s}^{-1}$, as described in [1], and it was found that their viscosity versus shear rate behaviour at a given temperature could be described by the Carreau-Yasuda equation [10]:

$\eta=\eta_{\infty}+\left(\eta_{0}-\eta_{\infty}\right)\left(1+(A \dot{\gamma})^{a}\right)^{\left(\frac{n-1}{a}\right)}$,

where $\eta$ is the dynamic viscosity of the fluid at the shear rate $\dot{\gamma}, \eta_{0}$ is the first Newtonian viscosity, $\eta_{\infty}$ is the second Newtonian viscosity (approximated to the viscosity of the blend's base oil) and $A, n$ and $a$ are the constants of fit. Figure 1 shows the viscosity shear rate results, together with Carreau-Yasuda best fits, for one of the test oils at four test temperatures.

It was also found that for all except one of the VM-containing oils the shear thinning curves at different temperatures could be collapsed onto a single master curve using time-temperature superposition in which the shear rate is multiplied by a shift factor $a_{T}$, to give a reduced shear rate, $\dot{\gamma}_{\mathrm{r}}=a_{T} \dot{\gamma}$. The shift factor $a_{T}$ is a shift from a reference temperature, $T_{\mathrm{R}}$, ( $60{ }^{\circ} \mathrm{C}$ in this study) at which $a_{T}$ is taken to be unity, and is defined by Eq. (2) [11]:

$a_{T}=\frac{\left[\eta_{0}-\eta_{\infty}\right]_{(T)}}{\left[\eta_{0}-\eta_{\infty}\right]_{\left(T_{\mathrm{R}}\right)}} \times \frac{T_{\mathrm{R}}}{T}$.
Table 1 VM-containing oils (\#1 to \#17) and the reference oil (\#18) studied

\begin{tabular}{lllllllll}
\hline Oil & VM type & VM (wt\%) & DI pack & DI pack (wt\%) & KV100C (cSt) & VI & Base oil type & HTHS (cP) \\
\hline$\# 1$ & SIP & 11.5 & - & - & 16.19 & 162 & G-II & 3.73 \\
$\# 2$ & SIP & 26.0 & - & - & 14.94 & 210 & G-II & 3.71 \\
$\# 3$ & SIP & 10.0 & - & - & 15.01 & 164 & G-II & 3.71 \\
$\# 4$ & SIP & 25.0 & - & - & 19.91 & 183 G-II & 3.70 \\
$\# 5$ & A-OCP & 11.5 & - & - & 13.60 & 153 G-II & 3.69 \\
$\# 6$ & A-OCP & 13.5 & - & - & 15.22 & 159 & G-II & 3.71 \\
$\# 7$ & D-PMA & 9.0 & - & - & 12.54 & 191 & G-II & 3.70 \\
$\# 8$ & A-OCP & 11.5 & - & - & 13.36 & 149 & G-II & 3.76 \\
$\# 9$ & SBR & 24.0 & - & - & 15.73 & 177 & G-II & 3.75 \\
$\# 10$ & PMA & 13.5 & - & - & 11.40 & 276 & G-II & 3.77 \\
$\# 11$ & VM in \#2 & 15.7 & D1 & 11.9 & 13.73 & 178 G-II & 3.73 \\
$\# 12$ & VM in \#2 & 17.2 & D1 & 11.9 & 12.93 & 180 & G-III & 3.69 \\
$\# 13$ & VM in \#2 & 19.7 & D1 & 11.9 & 12.70 & 175 & G-IV & 3.68 \\
$\# 14$ & VM in \#2 & 4.6 & D1 & 11.9 & 12.58 & 131 & G-II & 3.73 \\
$\# 15$ & VM in \#9 & 4.2 & D1 & 11.9 & 12.64 & 127 & G-II & 3.70 \\
$\# 16$ & VM in \#6 & 2.2 & D1 & 11.9 & 12.99 & 126 & G-II & 3.73 \\
$\# 17$ & VM in \#9 & 5.7 & D2 & 12.35 & 12.73 & 130 & G-II & 3.72 \\
$\# 18$ & - & - & - & - & 12.48 & 148 & G-IV & 3.70 \\
\hline
\end{tabular}

SIP hydrogenated styrene isoprene, $\mathrm{OCP}$ olefin copolymer, $\mathrm{PMA}$ polymethacrylate, SBR hydrogenated styrene butadiene, D- dispersant-, A- amorphous- 


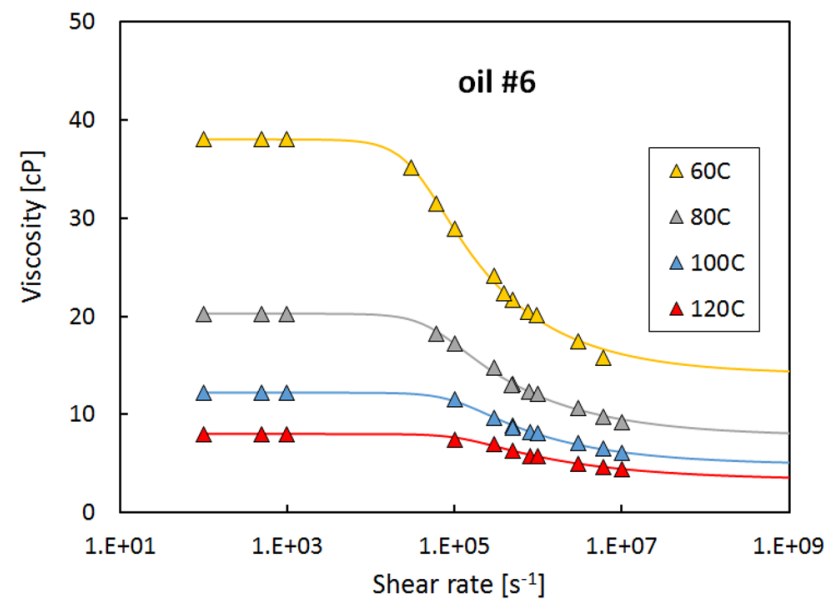

Fig. 1 Flow curves of oil \#6 at four temperatures

This allows a single reduced Carreau-Yasuda equation to be developed to describe how viscosity varies with both shear rate and temperature for a given VM blend:

$\eta=\eta_{\infty}+\left(\eta_{0}-\eta_{\infty}\right)\left(1+\left(A_{\mathrm{r}} a_{T} \dot{\gamma}\right)^{a_{\mathrm{r}}}\right)^{\left(\frac{n_{\mathrm{r}}-1}{a_{\mathrm{r}}}\right)}$,

where the three constants $A_{\mathrm{r}}, n_{\mathrm{r}}$ and $a_{\mathrm{r}}$ are now best fits to the measured viscosity values of the blend at all shear rates and temperatures. Figure 2 shows the viscosity data in Fig. 1 transformed using this approach. SSI, the shear stability index, is a normalised viscosity defined by

$S S I=\frac{\left(\eta-\eta_{\infty}\right)}{\left(\eta_{o}-\eta_{\infty}\right)}$,

while the solid line shows the fit of SSI to $\left(1+\left(A_{r} a_{T} \dot{\gamma}\right)^{a_{r}}\right)^{\left(\frac{n_{r}-1}{a_{r}}\right)}$ with $A_{r}=31 \mu \mathrm{s}, n_{r}=0.60$ and $a_{r}=1.58$.

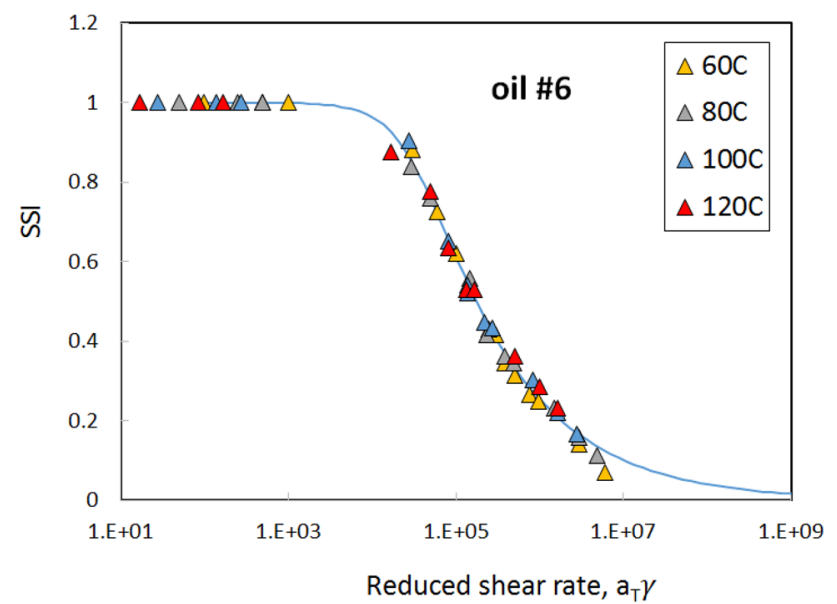

Fig. 2 Shear stability index, SSI, versus reduced strain rate for oil \#6

The above means that the viscosity of a VM blend can be calculated at any shear rate and temperature of interest so long as (i) the reduced Carreau-Yasuda constants, $A_{\mathrm{r}}, n_{\mathrm{r}}$ and $a_{\mathrm{r}}$ are known for the blend and (ii) the low shear rate viscosities $\eta_{0}$ and $\eta_{\infty}$ are known or can be calculated at the temperature of interest and at the reference temperature.

Table 2 lists the reduced Carreau-Yasuda constants for all of the tested VM blends. As discussed in [1], oil \#10 did not show satisfactory time-temperature superposition collapse using the shift factor expression in Eq. (2). This can be addressed by allowing $a_{T}$ for this oil to vary with temperature empirically, based on experimental measurements at different temperatures, rather than on Eq. (2). For oil \#10, viscosity can thus be predicted using the Carreau-Yasuda constants in Table 2, but taking $a_{T}$ to be $1,1.3,3.2,3.7$ and 3.7 at $60,80,100,120$ and $150{ }^{\circ} \mathrm{C}$, respectively, and allowing it to vary linearly with temperature between these bounding values at intermediate temperatures.

The required values of low shear rate viscosities $\eta_{0}$ and $\eta_{\infty}$ at both the temperature of interest and the reference temperature of $60^{\circ} \mathrm{C}$ can be straightforwardly calculated from the Vogel viscosity-temperature equation, Eq. (5), using the Vogel fit constants for each fluid and its base fluid as listed in Table 3.

$\eta_{0}=a_{0} e^{b_{0} /\left(T-c_{0}\right)}$

\section{Journal Bearing Model}

This study models a commercial engine bearing of length $L=17.8 \mathrm{~mm}$ and shaft diameter $D=59.0 \mathrm{~mm}$, corresponding to an $L / D$ ratio of $c a 0.30$. The radial clearance, $c$, was

Table 2 Reduced CarreauYasuda constants for VM blends (reference temperature $\left.T_{R}=60{ }^{\circ} \mathrm{C}\right)$

\begin{tabular}{lrll}
\hline Test oil & $A_{\mathrm{r}}(\mu \mathrm{s})$ & $n_{\mathrm{r}}$ & \multicolumn{1}{l}{$a_{\mathrm{r}}$} \\
\hline$\# 1$ & 21.88 & 0.36 & 1.00 \\
$\# 2$ & 78.52 & 0.64 & 2.50 \\
$\# 3$ & 10.96 & 0.40 & 1.00 \\
$\# 4$ & 68.39 & 0.47 & 1.00 \\
$\# 5$ & 18.41 & 0.66 & 1.52 \\
$\# 6$ & 30.90 & 0.60 & 1.58 \\
$\# 7$ & 21.13 & 0.75 & 2.26 \\
$\# 8$ & 19.72 & 0.67 & 1.80 \\
$\# 9$ & 34.28 & 0.47 & 1.37 \\
$\# 10$ & 1.70 & 0.69 & 1.60 \\
$\# 11$ & 39.36 & 0.75 & 2.50 \\
$\# 12$ & 31.99 & 0.75 & 2.13 \\
$\# 13$ & 33.11 & 0.75 & 2.50 \\
$\# 14$ & 24.27 & 0.88 & 2.50 \\
$\# 15$ & 26.92 & 0.88 & 2.50 \\
$\# 16$ & 26.92 & 0.88 & 2.13 \\
$\# 17$ & 25.12 & 0.84 & 2.50 \\
\hline
\end{tabular}


Table 3 Low-shear-rate Vogel constants of VM blends and component base oils

\begin{tabular}{|c|c|c|c|c|c|c|}
\hline \multirow[t]{2}{*}{ Test oil } & \multicolumn{3}{|c|}{ Vogel constants of test oil (to determine $\eta_{0}$ ) } & \multicolumn{3}{|c|}{ Vogel constants of base oil (to determine $\eta_{\infty}$ ) } \\
\hline & Vogel $a_{o}(\mathrm{cP})$ & Voge $b_{o}\left({ }^{\circ} \mathrm{C}\right)$ & $\operatorname{Vogel} c_{o}\left({ }^{\circ} \mathrm{C}\right)$ & Vogel $a_{o}(\mathrm{cP})$ & Vogel $b_{o}\left({ }^{\circ} \mathrm{C}\right)$ & Vogel $c_{o}\left({ }^{\circ} \mathrm{C}\right)$ \\
\hline$\# 1$ & 0.11158 & 989.308 & -107.84 & 0.06322 & 883.001 & -103.24 \\
\hline$\# 2$ & 0.31383 & 673.581 & -87.17 & 0.06322 & 883.001 & -103.24 \\
\hline$\# 3$ & 0.09507 & 1022.25 & -111.6 & 0.06322 & 883.001 & -103.24 \\
\hline \#4 & 0.12945 & 1028.18 & -113.64 & 0.06322 & 883.001 & -103.24 \\
\hline$\# 5$ & 0.0844 & 1024.21 & -110.63 & 0.06322 & 883.001 & -103.24 \\
\hline \#6 & 0.10288 & 995.216 & -108.31 & 0.06322 & 883.001 & -103.24 \\
\hline$\# 7$ & 0.161106 & 850.124 & -105.28 & 0.06322 & 883.001 & -103.24 \\
\hline$\# 8$ & 0.08168 & 1025.42 & -110.11 & 0.06322 & 883.001 & -103.24 \\
\hline \#9 & 0.10438 & 1021.68 & -113.94 & 0.06322 & 883.001 & -103.24 \\
\hline$\# 10$ & 1.13028 & 310.73 & -50.628 & 0.06322 & 883.001 & -103.24 \\
\hline \#11 & 0.19964 & 770.535 & -92.505 & 0.06322 & 883.001 & -103.24 \\
\hline$\# 12$ & 0.14727 & 858.854 & -102.66 & 0.05961 & 923.484 & -111.03 \\
\hline$\# 13$ & 0.09726 & 999.662 & -115.6 & 0.04642 & 1025.33 & -122.46 \\
\hline$\# 14$ & 0.0646 & 1054.26 & -108.11 & 0.05863 & 971.583 & -103.46 \\
\hline$\# 15$ & 0.07005 & 1025.97 & -105.35 & 0.05863 & 971.583 & -103.46 \\
\hline$\# 16$ & 0.06667 & 1045.59 & -106.07 & 0.05863 & 971.583 & -103.46 \\
\hline \#17 & 0.07264 & 1021.2 & -105.47 & 0.05969 & 1031.48 & -105.77 \\
\hline \#18 & 0.04839 & 1193.38 & -124.72 & - & - & - \\
\hline
\end{tabular}
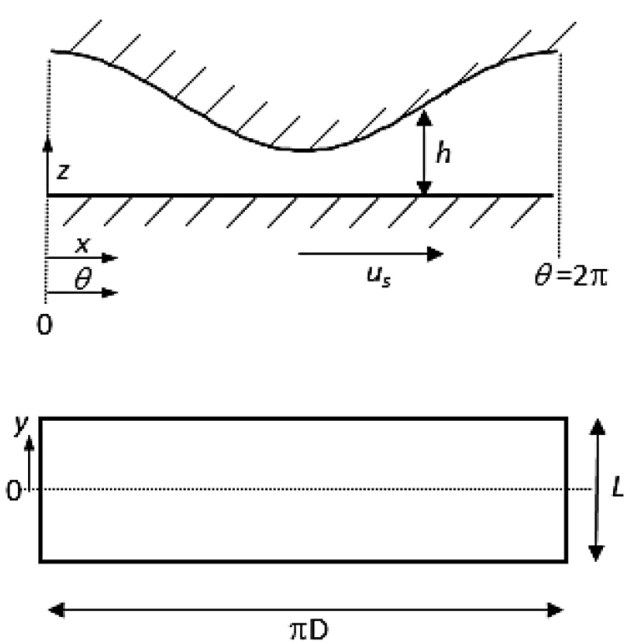

Fig. 3 Elevation and plan views of unwrapped bearing

$29 \mu \mathrm{m}$. These dimensions were chosen since this bearing was also studied experimentally in a journal bearing machine using the same VM-containing test oils as the current paper, as will be reported in a future publication. Steady-load, isothermal conditions were analysed. Figure 3 shows the unwrapped bearing and coordinate system used.

To determine the influence of shear thinning in a lubricated bearing, a hydrodynamic model is required that allows viscosity to vary within the fluid film. There are two principle ways of doing this. The simpler one uses the conventional Reynolds equation, Eq. (6), and allows the viscosity to vary across the bearing depending on the local shear rate, but not to vary through the thickness of the film. $h, p$ and $h$ are the pressure, film gap and viscosity at location $(x, y)$, respectively, while $u_{s}$ is the rotating shaft surface speed and the sleeve is stationary. In this equation, and also in Eq. (7) below, the density is assumed constant and there is no squeeze term. This conventional Reynolds variable viscosity approach was widely used in the 1970s to model journal bearings allowing for thermal effects [e.g. 12]:

$\frac{\partial}{\partial x}\left(\frac{h^{3}}{\eta} \frac{\partial p}{\partial x}\right)+\frac{\partial}{\partial y}\left(\frac{h^{3}}{\eta} \frac{\partial p}{\partial y}\right)=6 u_{\mathrm{s}} \frac{\mathrm{d} h}{\mathrm{~d} x}$.

A more sophisticated approach, originally developed by Dowson [13] and known as the generalized Reynolds equation, allows viscosity to vary also through the thickness of the lubricant film using integral equations to calculate the fluid flow terms. It has the form:

$\frac{\partial}{\partial x}\left(J \frac{\partial p}{\partial x}\right)+\frac{\partial}{\partial y}\left(J \frac{\partial p}{\partial y}\right)=u_{\mathrm{s}} \frac{\mathrm{d}}{\mathrm{d} x}\left(J_{\mathrm{R}}\right)$,

where $J$ and $J_{R}$ are given by

$J=\frac{J_{1 z h} J_{0}-J_{1} J_{0 z h}}{J_{0}}, J_{\mathrm{R}}=\frac{J_{0 z h}}{J_{0}}$

$$
\text { and } J_{0}=\int_{0}^{h} \frac{1}{\eta} \mathrm{d} z, J_{1}=\int_{0}^{h} \frac{z}{\eta} \mathrm{d} z \text {. }
$$

Here $z$ is the distance through the film from the bearing surface, $\eta$ is the viscosity at $(x, y, z)$ and $J_{0 z h}$ and $J_{1 z h}$ 
are double integral expressions of the viscosity through the thickness of the film $h$ at each $(x, y)$ location given by

$J_{o z h}=\int_{o}^{h} J_{0 z} \mathrm{~d} z, J_{1 z h}=\int_{o}^{h} J_{1 z} \mathrm{~d} z$

where $J_{0 z}=\int_{0}^{z} \frac{1}{\eta} \mathrm{d} z$ and $J_{1 z}=\int_{0}^{z} \frac{z}{\eta} \mathrm{d} z$.

Equation 7 reduces to Eq. (6) when the viscosity is taken to be independent of $z$ in the integral expressions for $J_{1 z}, J_{0 z}$, $J_{1 z h}$ and $J_{0 z h}$.

This generalised Reynolds equation has been widely used to model thermal bearings [13-15] and has also been employed to explore the impact on film thickness and friction of thick, viscous boundary films [16, 17].

All of the results reported in this paper were obtained using the generalised Reynolds equation, Eq. (7). This was solved to determine the fluid film pressure using central finite difference, with the boundary conditions $p=0$ at $x=0$ and at $y= \pm L / 2$ and the conventional computing Reynolds exit boundary condition; if $p<0 p=0$, corresponding to $p=0, \mathrm{~d} p / \mathrm{d} x=0$.

The viscosity was determined at each $(x, y, z)$ location using the reduced Carreau-Yasuda equation (Eq. 3 ) and the shear rate was determined from the local velocity gradient:

$\dot{\gamma}=\left(\left(\frac{\partial u}{\partial z}\right)^{2}+\left(\frac{\partial v}{\partial z}\right)^{2}\right)^{0.5}$

where

$\frac{\partial u}{\partial z}=\frac{u_{s}}{J_{o} \eta}+\frac{\partial p}{\partial x}\left(\frac{z}{\eta}-\frac{J_{1}}{J_{o} \eta}\right)$ and $\frac{\partial v}{\partial z}=\frac{\partial p}{\partial y}\left(\frac{z}{\eta}-\frac{J_{1}}{J_{o} \eta}\right)$.

Within the main solution, at each location Eqs. (10), (11) and (3) were solved iteratively to establish a converged solution for the local viscosity; typically about 3 to 4 iterations were needed.

Friction was determined as that acting on the rotating shaft from

$F=\int_{\text {full }} \tau_{x} \mathrm{~d} x \mathrm{~d} y$

where $\tau_{x}$ is the shear stress at the rotor wall and is given by

$\tau_{x}=\frac{u_{s}}{J_{o}}+\frac{\partial p}{\partial x}\left(h-\frac{J_{1}}{J_{o}}\right)$

The term "full" in Eq. 12 indicates that the integration was made over the region of the bearing that was full of oil. This raises a significant problem in determining the friction in hydrodynamic bearings, where cavitation occurs when the pressure falls to zero just after the minimum film thickness. Two questions arise: (a) Where does the cavitated zone reform as an inlet meniscus? (b) Does the oil passing through the minimum form streamers that bridge the gap between the rotor and the bush, in which case they will contribute to friction, or does it split into separate films on the converging surfaces of the rotor and bearing?

Concerning (a), it is often assumed either that oil fills the whole bearing or that it fills half of the bearing from the maximum film thickness position $\theta=0(x=0)$. The latter fails, however, to take account of the fact that the rotor position moves from the applied load line to establish an attitude angle, which in this study was generally about $30^{\circ}$ to $50^{\circ}$. This means that during steady running the oil inlet port, which is generally at $\theta=0$ when the bearing is stationary, is about $40^{\circ}$ upstream of the maximum film thickness. The current study assumes that the inlet meniscus forms as a straight line across the bearing length at this upstream position based on the calculated attitude angle.

Issue (b) above is more problematic and can have a considerable effect on the overall friction, with a full set of streamers adding $30-40 \%$ to the total friction. In this study, the friction values given are based on the assumption that streamers are present in the cavitated zone, as noted in many studies [18]. This assumption is arbitrary, but since most friction originates from Couette shear, assuming similar wetting properties, the absence of streamers is likely to result in a similar proportionate decrease in friction for all test oils. The proportion of the bearing length bridged by streamers at gap $h$ was calculated by integrating the flow through the minimum film region of the bearing and allowing this to fill a fraction of the downstream region based on the local gap, i.e. assuming no loss of fluid downstream of the minimum film thickness. For the VM-containing oil, shear thinning was assumed to occur in the streamers based on the local velocity gradient, $\mathrm{d} u / \mathrm{d} z$, with viscosity determined by Eq. (3).

At the loads, speeds and viscosities used, the highest pressure reached was ca $15 \mathrm{MPa}$ implying a very small and localised piezoviscous contribution. In the current paper, this is neglected since it will influence all the oils similarly and the interest was only to compare the different VMs.

\section{Results}

Figure 4 shows the pressure, Couette friction and Poiseuille friction maps across the bearing lubricated with oil \#4 at a speed of $3000 \mathrm{rpm}$, load of $2 \mathrm{kN}$ and temperature of $100{ }^{\circ} \mathrm{C}$. In all cases, the rotating shaft moves from the left to right so the pressurised or "active" zone is in the left half of the map. The friction is shown as positive when it acts against the shaft rotation. The Couette friction originates from the 
(a)

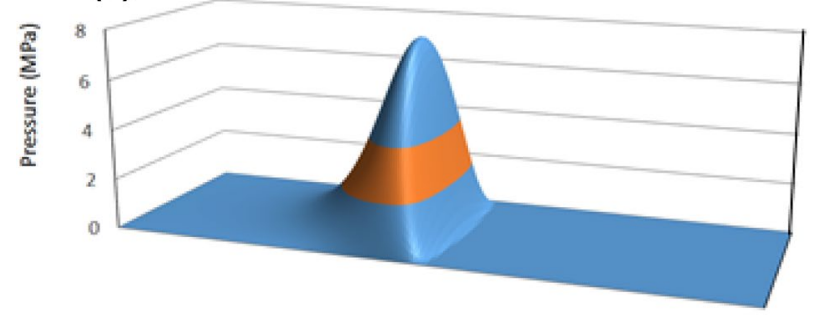

(b)

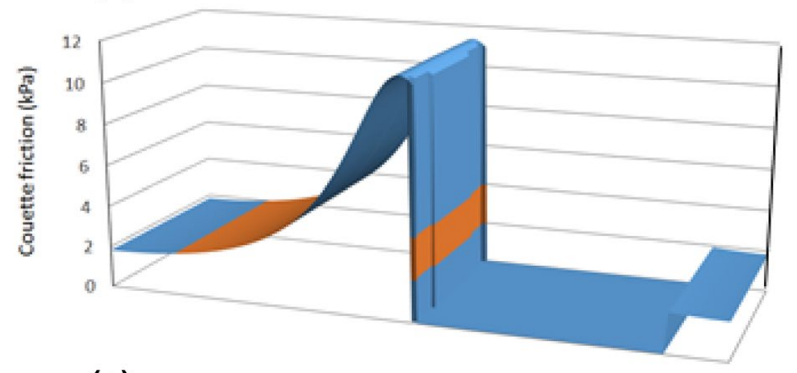

(c)

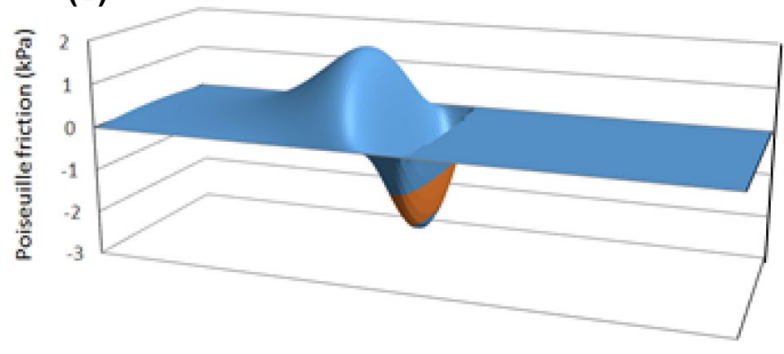

Fig. 4 Maps to illustrate a fluid pressure, b Couette friction and c Poiseuille friction for bearing at $3000 \mathrm{rpm}, 2 \mathrm{kN}$ load and $100{ }^{\circ} \mathrm{C}$, lubricated by oil \#4

first term in Eq. (13) and the Poiseuille friction from the second term. In the Couette friction map, the effect of the streamers is not shown but the friction due to the shift of the inlet supply location as the bearing rotates under load is indicated. The Poiseuille friction on the shaft acts to brake the shaft when $\mathrm{d} p / \mathrm{d} x$ is positive and then to accelerate it when $\mathrm{d} p / \mathrm{d} x$ is negative.

Figure 5 shows the predicted influence of shear thinning on minimum film thickness, $h_{o}$, and friction, $F$, for the test bearing lubricated by test oil \#6 over a range of bearing speeds at $2 \mathrm{kN}$ load and $80{ }^{\circ} \mathrm{C}$. Also shown are the film thickness and friction predicted where oil \#6 does not show any shear thinning (i.e. based on its $\eta_{0}$ value) and those of its VM-free base oil. Both film thickness and friction are reduced significantly when shear thinning occurs, especially at high bearing speeds.

The practical effect of this shear thinning is actually considerably greater than that shown in Fig. 5 since the bearing power loss is the product of friction and bearing speed. Figure 6 shows the variation of power loss with bearing speed

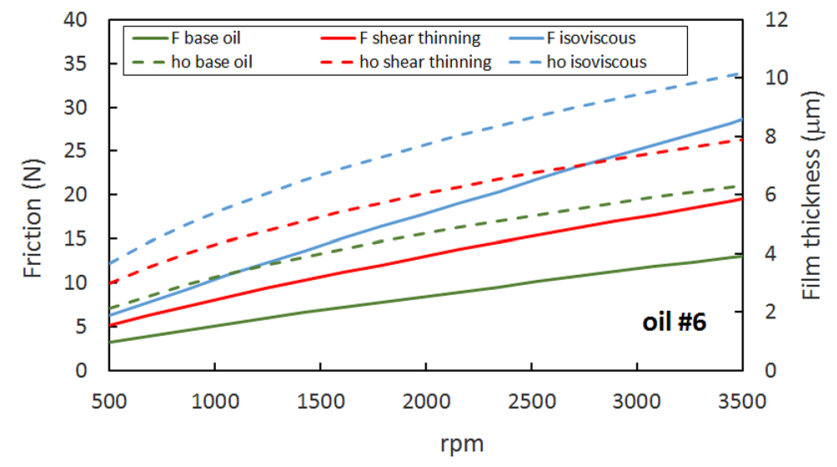

Fig. 5 Variation of friction and minimum film thickness with shaft speed for shear thinning oil \#6, its isoviscous equivalent and its base oil, all at $80{ }^{\circ} \mathrm{C}$ and $2 \mathrm{kN}$ load

and it can be seen that the effect of shear thinning becomes quite large at high speeds.

Figure 7 shows the cross-plots of friction versus minimum film thickness for the bearing lubricated with oil \#6 at $80^{\circ} \mathrm{C}$ and $2 \mathrm{kN}$ load over a range of bearing speeds, comparing predictions when the VM solution shear thins and when it does not. It can be seen that the relationship between friction and film thickness is only very slightly dependent on shear thinning, i.e. shear thinning influences the both similarly. The practical effect of shear thinning is to reduce both friction and film thickness at high sliding speeds.

Figure 8 shows the influence of load on the friction of the bearing lubricated by oil \#6 at $3000 \mathrm{rpm}$ and $80{ }^{\circ} \mathrm{C}$. Shear thinning reduces friction greatly, especially at high loads. However, the film thickness debit resulting from shear thinning is relatively insensitive to applied load.

Figure 9 shows how film thickness and friction vary with oil temperature at $3000 \mathrm{rpm}$ and $2 \mathrm{kN}$ load. A reduction of friction due to shear thinning occurs at all temperatures but becomes particularly marked at low temperature, to reach a $30 \%$ reduction at $60{ }^{\circ} \mathrm{C}$.

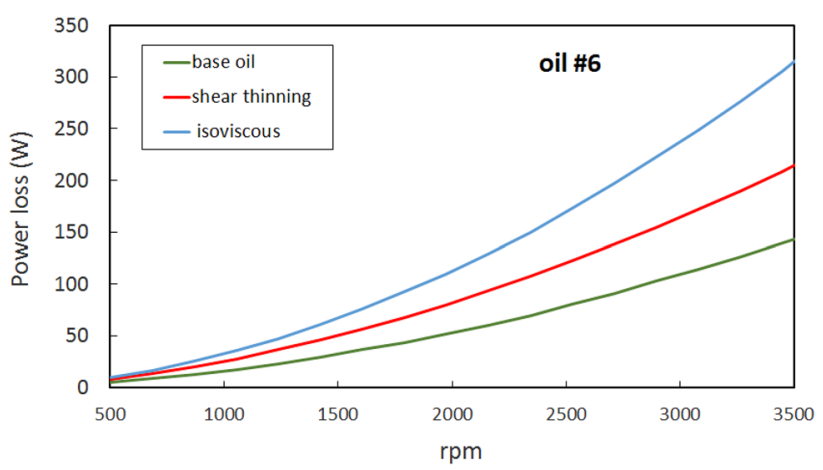

Fig. 6 Variation of power loss with shaft speed for shear thinning oil $\# 6$ and its isoviscous equivalent, both at $80^{\circ} \mathrm{C}$ and $2 \mathrm{kN}$ load 


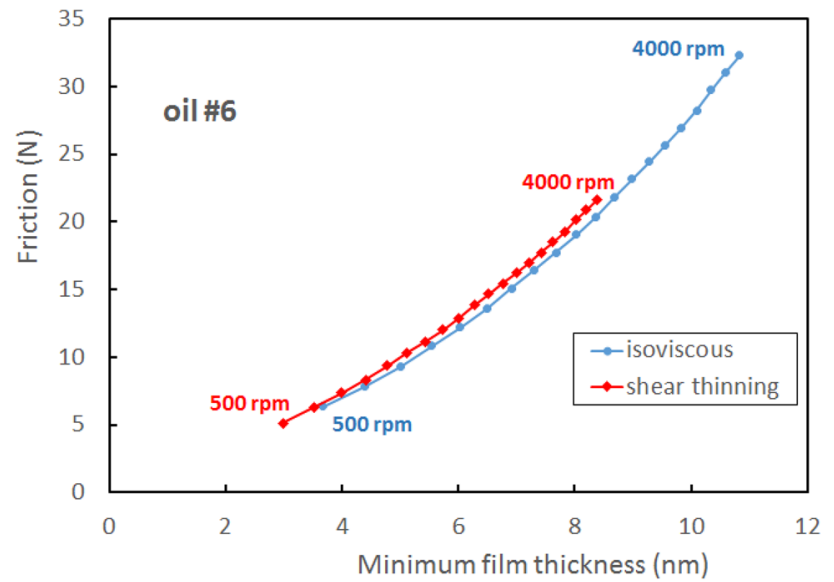

Fig. 7 Variation of friction with minimum film thickness over a range of shaft speeds for shear thinning oil \#6 and its isoviscous equivalent at $80{ }^{\circ} \mathrm{C}$ and $2 \mathrm{kN}$ load

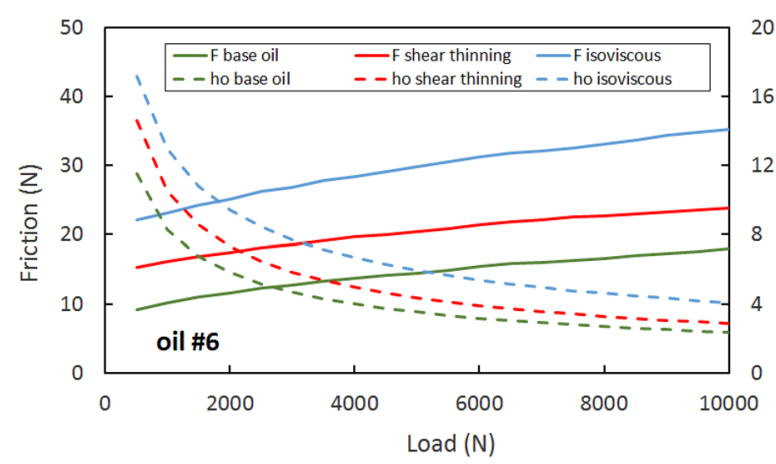

Fig. 8 Variation of minimum film thickness and friction with load for shear thinning oil \#6 and its isoviscous equivalent at $3000 \mathrm{rpm}$ and $80^{\circ} \mathrm{C}$

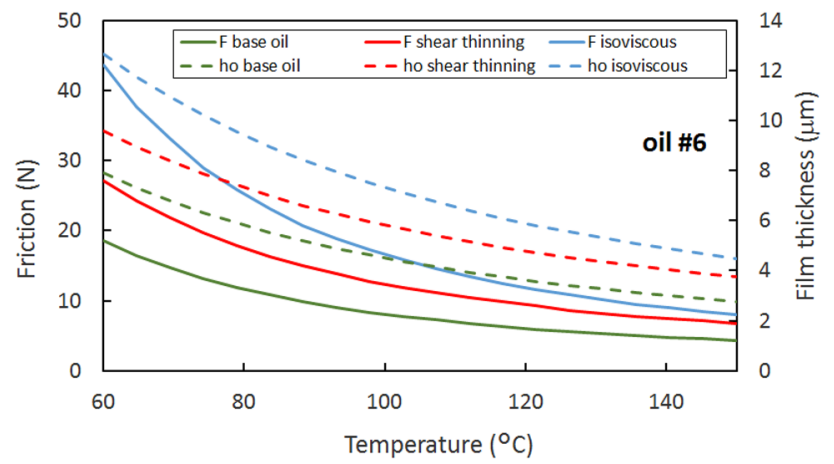

Fig. 9 Variation of minimum film thickness and friction with temperature for shear thinning oil \#6 and its isoviscous equivalent at $3000 \mathrm{rpm}$ and $2 \mathrm{kN}$

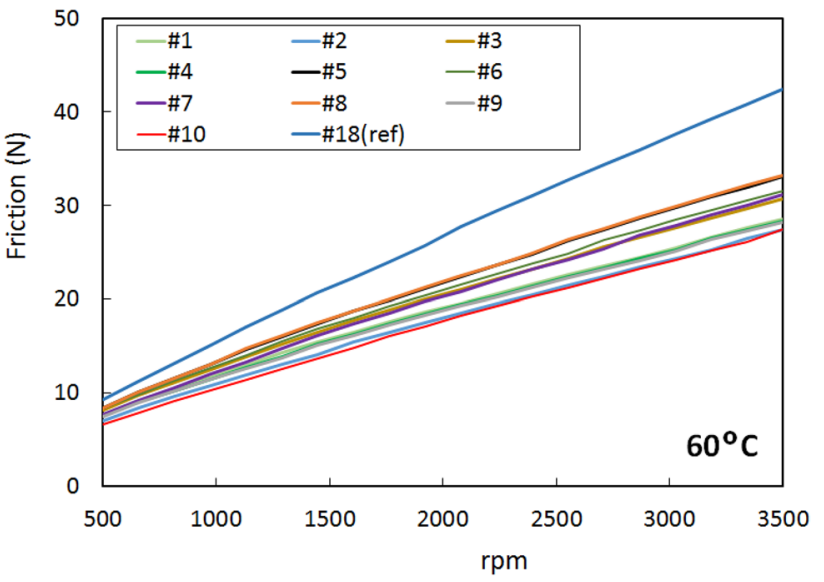

Fig. 10 Friction of test oils at $3 \mathrm{kN}$ load and $60^{\circ} \mathrm{C}$

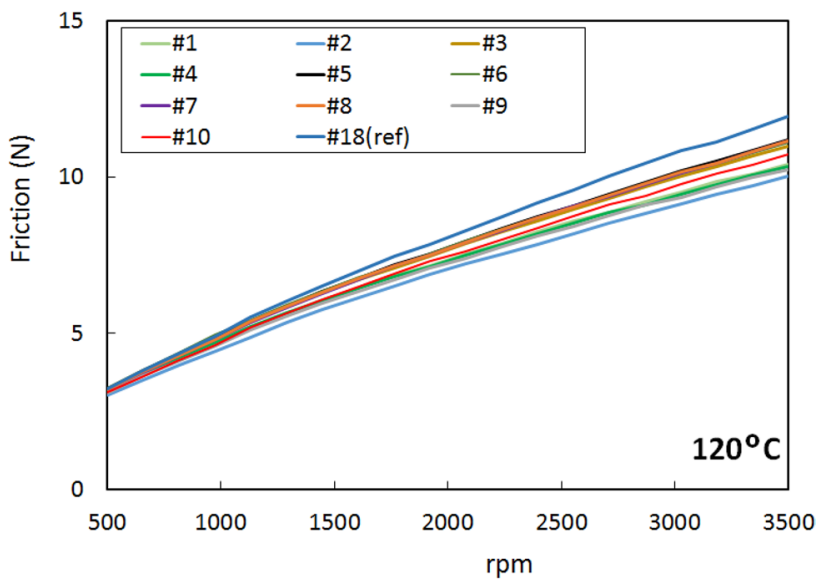

Fig. 11 Friction of test oils at $3 \mathrm{kN}$ load and $120^{\circ} \mathrm{C}$

Figures 10 and 11 compares the predicted friction of all of the simple VM blends at $60{ }^{\circ} \mathrm{C}$ and $120{ }^{\circ} \mathrm{C}$, respectively. All VM-containing oils give lower friction than the reference oil at both temperatures. At $60{ }^{\circ} \mathrm{C}$, there are considerable differences between the VM-containing oils, with a $22 \%$ difference at $3500 \mathrm{rpm}$ between the one with the lowest friction (oil \#10) and the highest (oils \#5 and \#8, which are superimposed). At $120^{\circ} \mathrm{C}$, there is less difference since all oils have the same HTHS and the temperature of $120^{\circ} \mathrm{C}$ is approaching $150{ }^{\circ} \mathrm{C}$ at which HTHS is measured. However, at $3000 \mathrm{rpm}$ there is still a difference of $8 \%$ between the highest (oils \#5 and \#8) and the lowest (oil \#2).

Figure 12 compares friction at $3000 \mathrm{rpm}$ and $3 \mathrm{kN}$ at 60 and $120^{\circ} \mathrm{C}$ for all of the test oils. At $60{ }^{\circ} \mathrm{C}$, some of the blends approach the very low friction of the base oil \#1-11b, the base of oils \#1 to \#11. The four fully formulated oils \#14 to \#17 give higher friction than the others due to their relatively high-viscosity base oil. At $120^{\circ} \mathrm{C}$, all the 
Fig. 12 Friction of test oils at $3000 \mathrm{rpm}, 3 \mathrm{kN}$ load and two different temperatures: a $60{ }^{\circ} \mathrm{C}$ and $\mathbf{b} 120^{\circ} \mathrm{C}$
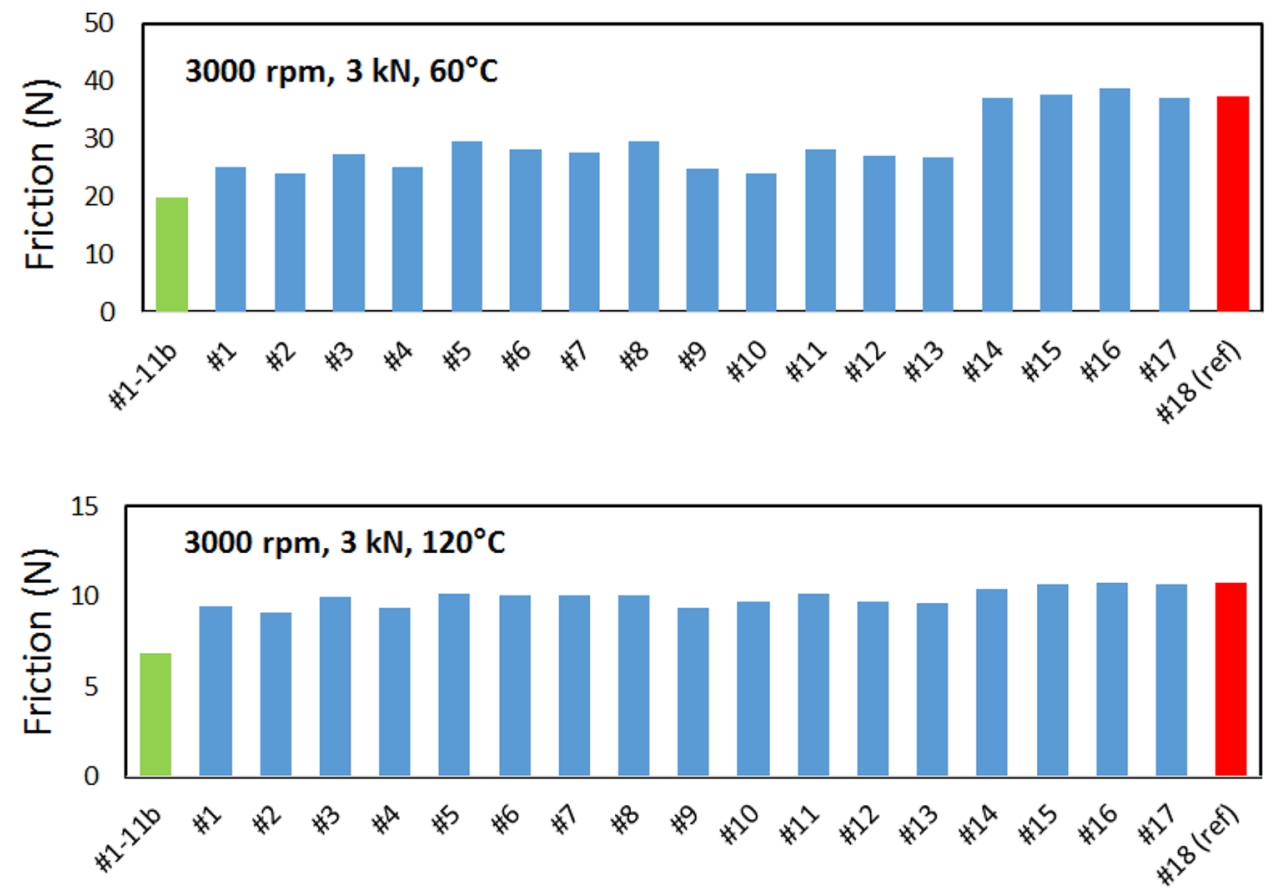

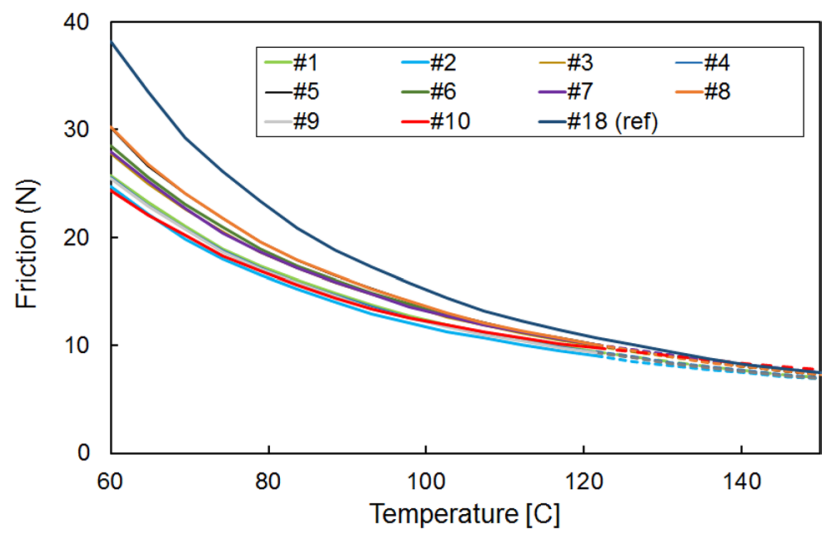

Fig. 13 Variation of friction with oil temperature for VM blends \#1 to $\# 10$. Shaft speed $=3000 \mathrm{rpm}$, applied load $=3 \mathrm{kN}$

VM-containing oils give quite similar friction, as expected, since they are all formulated to the same HTHS.

Figure 13 makes use of the time-temperature superposition-based shear thinning equation, Eq. (3), to compare the effect of temperature on friction for the ten simple VM blends. Also shown are the base oil and the reference oil \#18. For oil \#10, which did not obey time-temperature superposition, the line is calculated based on the assumption that $a_{T}$ varies linearly between the values calculated from the fits at $60,80,100$ and $120^{\circ} \mathrm{C}$ as described in Sect. 2. The curves above $120^{\circ} \mathrm{C}$ are shown as dashed since they are extrapolations. There are considerable differences in friction between the VMs at low temperatures, but except for the base oil the values appear to converge at $150{ }^{\circ} \mathrm{C}$, as might be expected.

\section{Discussion}

\subsection{Film Thickness}

Ideally, the addition of a VM thickener should increase viscosity (and thus film thickness) at low bearing speeds, when film thickness and thus shear rate are low, but shear thin to reduce friction and power loss at high speeds when a thick film will be formed by virtue of the high speed. One issue of interest is therefore the extent to which the addition of a VM to a low-viscosity base oil enhances oil film thickness at low bearing speeds.

Figure 14 shows the minimum film thickness at two, very low, shaft speeds and $3 \mathrm{kN}$ load for all the test oils. At the shaft speeds of $10 \mathrm{rpm}$ and $100 \mathrm{rpm}$ (corresponding to the sliding speeds of 0.03 and $0.3 \mathrm{~m} \mathrm{~s}^{-1}$ ), the VM-containing oils form films of similar thickness to the reference oil, indicating that there is very little effect due to shear thinning. At these film thicknesses, the maximum shear rate experienced by the polymers solutions is $c a 6 \times 10^{5} \mathrm{~s}^{-1}$ at $10 \mathrm{rpm}$ and $7 \times 10^{5} \mathrm{~s}^{-1}$ at $100 \mathrm{rpm}$, whereas it is ca $2.5 \times 10^{6} \mathrm{~s}^{-1}$ at $3000 \mathrm{rpm}$. The VMs are thus performing their desired role of shear thinning to reduce friction at high bearing speeds, but not shear thinning enough to detrimentally reduce film thickness at low bearing speeds.

\subsection{Origins of friction reduction with VM blends}

Figures 10, 11, 12 and 13 show the very significant impact on friction of VMs, especially at low temperature. They suggest that a VM additive can reduce friction in two separate 
Fig. 14 Minimum oil film thickness of test oils at low speeds, $3 \mathrm{kN}$ load and $120^{\circ} \mathrm{C}$
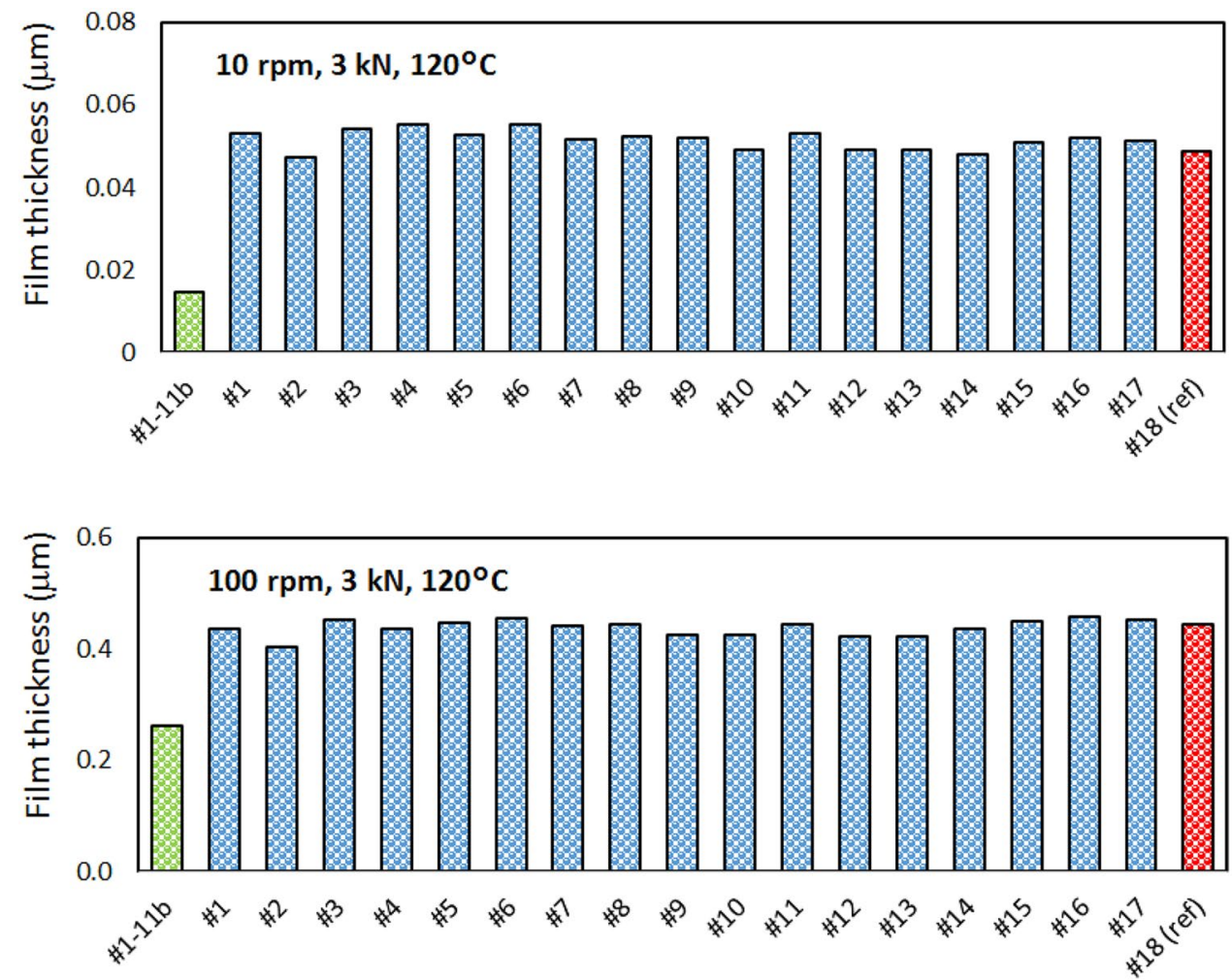

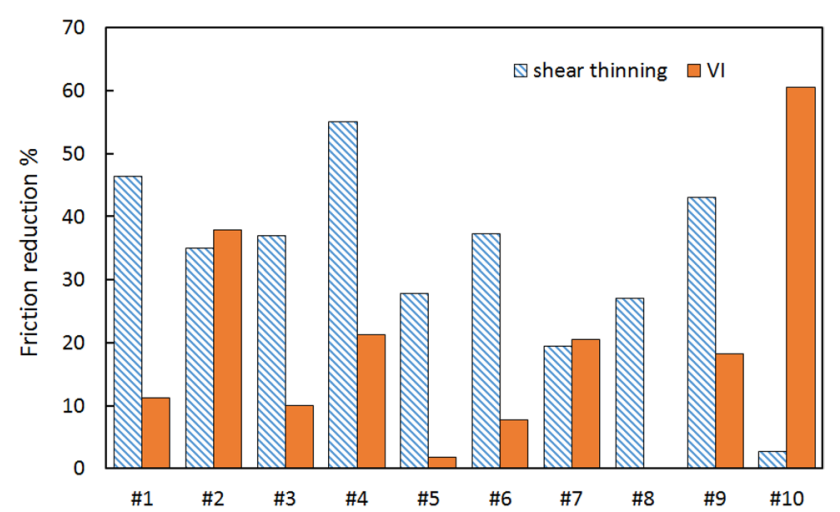

Fig. 15 Estimated friction reduction due to (i) shear thinning and (ii) VI increase for ten VM solutions at $60{ }^{\circ} \mathrm{C}, 3000 \mathrm{rpm}$ and $2 \mathrm{kN}$ load

ways, by shear thinning and by an increase in viscosity index. This is indicated in the $60{ }^{\circ} \mathrm{C}$ histogram in Fig. 12. Oil \#4 gives low friction because it shear thins relatively easily, so that at high shaft speeds and thus shear rates it gives low hydrodynamic friction. However, oil \#10 shows low friction because it has a very high viscosity index, which means that, since all the oils have the similar viscosity at $150{ }^{\circ} \mathrm{C}$, it has a relatively low viscosity at lower temperatures. These two different methods by which VMs may reduce friction have been previously noted by Taylor [19].

Figure 15 shows an attempt to quantify these two different friction reduction contributions for oils \#1 to \#10 at
$3000 \mathrm{rpm}, 2 \mathrm{kN}$ load and $60^{\circ} \mathrm{C}$. The friction reduction due to shear thinning was quite straightforwardly evaluated using the bearing model to calculate friction for each oil (i) allowing shear thinning, $F_{\text {shear thinning }}$, and (ii) based on the lowshear-rate viscosity of the oil at $60{ }^{\circ} \mathrm{C}, F_{\text {isoviscous }}$. Friction reduction is then given by Eq. (13):

Friction reduction due to shear thinning \%

$$
=\frac{F_{\text {isoviscous }}-F_{\text {shear thinning }}}{F_{\text {isoviscous }}} \times 100 \text {. }
$$

For the VM solutions \#1 to \#10, this friction reduction ranges from $55 \%$ to less than $5 \%$ and varies roughly with the relaxation times listed in Table 7, i.e. oils with long relaxation times show most shear thinning and so most friction reduction.

It is less straightforward to estimate the friction reduction resulting from the increase of VI due to the addition of polymer since the oils were blended to have the same HTHS rather than the same low-shear-rate viscosity and are thus not directly comparable. As an approximate estimate, the theoretical friction at $60^{\circ} \mathrm{C}$ assuming no shear thinning, $F_{\text {isoviscous, }}$, was compared with the value for an oil having the same low-shear-rate dynamic viscosity at $150{ }^{\circ} \mathrm{C}$ as the test oil but with $\mathrm{VI}=120$, $F_{\text {isoviscous,VI=120. }}$. The percentage friction reduction at $60^{\circ} \mathrm{C}$ due to VI increase is then 


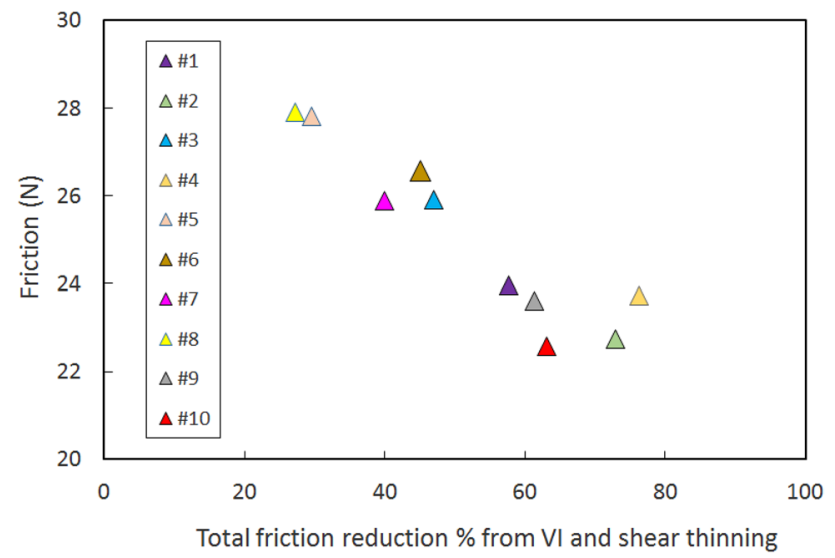

Fig. 16 Calculated bearing friction versus the sum of estimated friction reduction due to shear thinning and VI increase for ten VM solutions at $60{ }^{\circ} \mathrm{C}, 3000 \mathrm{rpm}$ and $2 \mathrm{kN}$ load

Friction reduction due to VI increase \%

$$
=\frac{F_{\text {isoviscous, } \mathrm{VI}=120}-F_{\text {isoviscous }}}{F_{\text {isoviscous, } \mathrm{VI}=120}} \times 100 \text {. }
$$

It can be seen, as expected, that most of the low friction of oil \#10 at $60^{\circ} \mathrm{C}$ originates from its low value of low-shearrate viscosity at that temperature due to its very high VI. Oils \#2, \#4 and \#7 also have a considerable contribution to friction reduction from their high VIs. By contrast, oils \#5, \#6 and \#8, which have relatively low VIs, obtain almost all of their friction reduction from shear thinning. With respect to the VMs themselves, oils \#5, \#6 and \#8 contain the three linear OCPs, while oils \#4 and \#9 are both linear diblocks that show a combination of considerable shear thinning and relatively high VI.

As the confirmation of the general validity of this split of friction reduction into two components, Fig. 16 shows the calculated overall bearing friction at $60{ }^{\circ} \mathrm{C}, 3000 \mathrm{rpm}$ and 2 $\mathrm{kN}$ load plotted against the sum of the two friction-reducing components shown in Fig. 15. There is a good inverse correlation between friction and the estimated friction reduction.

\section{Conclusions}

Using a hydrodynamic lubrication model applied to an engine bearing in conjunction with the experimentally measured viscosity versus shear rate curves, it is found that viscosity modifier additives (VMs) reduce friction and especially power loss markedly at high shaft speeds while still contributing to increased hydrodynamic film thickness at low speeds.

The model indicates that VMs can contribute to reducing friction in two separate ways: One is via shear thinning. This occurs especially at high engine speeds when shear rates are high and can result in a 50\% friction reduction at low temperatures for the blends studied. The second is via their impact on viscosity index, which means that for a set viscosity at high temperature (HTHS), the viscosity of a high-VI oil and thus its hydrodynamic friction will be lower at low temperatures than that of a low-VI one. This insight should assist in the development of fuel-efficient VM additives and their informed use.

Acknowledgements The authors would like to thank Repsol S.A. for supporting this work and supplying base fluids and additives.

Open Access This article is distributed under the terms of the Creative Commons Attribution 4.0 International License (http://creativeco mmons.org/licenses/by/4.0/), which permits unrestricted use, distribution, and reproduction in any medium, provided you give appropriate credit to the original author(s) and the source, provide a link to the Creative Commons license, and indicate if changes were made.

\section{References}

1. Marx, N., Fernández, L., Barceló, F., Spikes, H.A.: Shear thinning and hydrodynamic friction of viscosity modifier-containing oils. Part I: shear thinning behaviour. Tribol. Lett. (2018). https://doi. org/10.1007/s11249-018-1039-5

2. Stambaugh, R.L., Kinker, B.G.: Viscosity index improvers and thickeners. In: Mortier, R.M., Fox, M.F., Orszulik, S.T. (eds.) Chemistry and Technology of Lubricants, 3rd edn. Springer, New York (2010)

3. Mueller, H.G.: Mechanism of action of viscosity index improvers. Tribol. Int. 11, 189-192 (1978)

4. Covitch, M.J., Trickett, K.J.: How polymers behave as viscosity index improvers in lubricating oils. Adv. Chem. Eng. Sci. 5(02), 134-151 (2015)

5. Martini, A., Ramasamy, U.S., Len, M.: Review of viscosity modifier lubricant additives. Tribol. Lett. 66, 58 (2018)

6. Spearot, J.A.: High-temperature, high-shear (HTHS) oil viscosity: measurement and relationship to engine operation. ASTM Int., 1068, 1989

7. Taylor, R.I., Coy, R.C.: Improved fuel efficiency by lubricant design: a review. Proc. Inst. Mech. Eng. 214, 1-15 (2000)

8. De Carvalho, M.J.S., Seidl, P.R., Belchior, C.R.P., Sodré, J.R.: Lubricant viscosity and viscosity improver additive effects on diesel fuel economy. Tribol. Int. 43, 2298-2302 (2010)

9. Van Dam, W., Miller, T., Parsons, G.M., Takeuchi, Y.: The impact of lubricant viscosity and additive chemistry on fuel economy in heavy duty diesel engines. SAE Int J. Fuels Lubr. 5, 459-469 (2012)

10. Yasuda, K.Y., Armstrong, R.C., Cohen, R.E.: Shear flow properties of concentrated solutions of linear and star branched polystyrenes. Rheol. Acta 20, 163-178 (1981)

11. Bird, R.B.: Dynamics of polymeric liquids: fluid mechanics vol. 1. Chapter 3.6. 2nd edn. Wiley Interscience, New York (1987)

12. Stokes, M.J., Ettles, C.M.M.: A general evaluation method for the diabatic journal bearing. Proc. R. Soc. Lond. A 336, 307-325 (1974)

13. Dowson, D.: A generalized Reynolds equation for fluid-film lubrication. Intern. J. Mech. Sci. 4, 159-170 (1962)

14. Ferron, J., Frene, J., Boncompain, R.: A study of the thermohydrodynamic performance of a plain journal bearing comparison between theory and experiments. Trans ASME J. Lubr. Technol. 105, 422-428 (1983)

15. Monmousseau, P., Fillon, M., Frene, J.: Transient thermoelastohydrodynamic study of tilting-pad journal bearings - comparison between experimental data and theoretical results. Trans ASME J. Tribol. 119, 401-407 (1997) 
16. Qingwen, Q., Yahong, H., Jun, Z.: An adsorbent layer model for thin film lubrication. Wear 221, 9-14 (1998)

17. Ingram, M., Noles, J., Watts, R., Harris, S., Spikes, H.A.: Frictional properties of automatic transmission fluids: part 2: origins of friction-sliding speed behaviour. Tribol. Trans. 54, 154-167 (2011)
18. Dowson, D., Taylor, C.M.: Cavitation in bearings. Ann. Rev. Fluid Mech. 11, 35-65 (1979)

19. Taylor, R.I., de Kraker, B.R.: Shear rates in engines and implications for lubricant design. Proc. Inst. Mech. Eng. Part J. 231, 1106-1111 (2017) 